This item was submitted to Loughborough's Research Repository by the author.

Items in Figshare are protected by copyright, with all rights reserved, unless otherwise indicated.

\title{
Examination physical education: adhering to pedagogies of the classroom when coming in from the cold
}

PLEASE CITE THE PUBLISHED VERSION

http://dx.doi.org/10.1080/17408989.2013.837439

\section{PUBLISHER}

Taylor and Francis / @ Association for Physical Education

\section{VERSION}

AM (Accepted Manuscript)

\section{PUBLISHER STATEMENT}

This work is made available according to the conditions of the Creative Commons Attribution-NonCommercialNoDerivatives 4.0 International (CC BY-NC-ND 4.0) licence. Full details of this licence are available at: https://creativecommons.org/licenses/by-nc-nd/4.0/

\section{LICENCE}

CC BY-NC-ND 4.0

\section{REPOSITORY RECORD}

Casey, Ashley, and Toni M. O'Donovan. 2019. "Examination Physical Education: Adhering to Pedagogies of the Classroom When Coming in from the Cold”. figshare. https://hdl.handle.net/2134/19540. 


\section{Examination Physical Education: Adhering to pedagogies of the classroom when coming in from the cold}

\section{Structured Abstract}

Background: Green (2005) and Thorburn (2007) claim that examination physical education now holds a dominant place in both the UK's national discourse and in the lives and careers of many teachers. Despite the move towards the academicization of physical education and the proliferation of accredited qualifications in a number of countries, both of which have been celebrated by many physical educators, there is little research that investigates the actual process of teaching such courses.

Purpose: The purpose of this paper is to explore how pedagogical change in examination physical education using collaborative learning was experienced by, and impacted on, pupils and teachers in one school during a year long, assessed unit of Advanced Subsidiary Level ${ }^{\mathrm{i}}$ (AS Level) physiology and anatomy that formed part of a wider examination course in physical education.

Methodology: The study took place in a comprehensive secondary school in the SouthEast of England. With support from his Head of Department, a teacher attempted to modify his pedagogical approach away from the didactic approach that dominated his classroom-based teaching of AS Level physical education. Interviews were undertaken with the teacher and the head of department both before the start of the course and after the exam results were published. Additionally each student $(n=5)$ was interviewed and a wiki (which had been set up as a platform for collaborative learning within the group) was analysed for content and usage. The interviews were transcribed verbatim and each was independently analysed by the researchers. Data were subject to inductive analysis and constant comparison (Lincoln \& Guba, 1985) and key themes were drawn from this process.

Findings: The paper examines the concerns about performance and engagement of pupils with AS physical education and interrogates the teacher's beliefs about the underpinning pedagogical issues in the teaching of this course. The teacher's expressed concern about the pedagogical knowledge and subject matter content knowledge for anatomy and physiology units. The process of changing the traditional teaching styles adopted for this unit is explored from both teacher and pupil perspectives. Finally we consider the impact of the pedagogical changes on teachers, pupils and examination results.

Keywords: Examination, academicization, subject matter content knowledge, collaborative learning, technology, cooperative learning 


\section{Introduction}

Physical education has long been positioned on the margins of school provision (Lux \& McCullick, 2011; Penney, 2012; Rimmer, 2013). Indeed as one of the 'black sheep’ of the family of curriculum subjects (Carroll, 1994; Choi, 1992; Kretchmar, 1998) physical education has repeatedly sought to be seen as a legitimate subject with equal standing to its traditionally more highly valued siblings taught in our schools and universities. As other authors have previously highlighted (Brown \& Penney, 2013; Green, 2005; MacPhail, 2004; Thorburn, 2007) physical education has begun to address this 'marginality' and has sought recognition through the teaching of high stakes examinations at key exit points in students’ school careers - most significantly at those that decide on entry into post-mandatory and tertiary level education.

The existence, and in some countries the proliferation, of such examinations has significantly changed the landscape for teaching and learning in physical education (MacPhail, 2007), particularly in the UK, Australia and New Zealand. Internationally we have witnessed a focus on assessment in schools in an effort to increase opportunities for young people to stay in education beyond the mandatory leaving age (16 in the case of the UK). This drive has led to a diversification in the types of outcomes available to senior secondary school students in physical education. In his work on assessment Carroll (1994) noted the change in the education of 14-16 year olds that had occurred in England and Wales with the introduction of the General Certificate in Education (GCE) in physical education at the beginning of the 1970s. By the mid to late 1980s the introduction of General Certificates in Secondary Education (GCSE) and Advanced Level (A Level) courses established physical education’s place in the portfolio of academic subjects available to schools. 
While 'core' physical education in the UK remains, and is still assessed primarily through performance outcomes, the new ways of packaging and delivering physical education (Velija and Kumar 2009) have rapidly increased in popularity. Indeed, in its first year as an examinable subject in the UK Advanced level (A Level) physical education was taken by 34 students (Carroll 1994). In the summer of 2011 nearly 21,000 students took the subject. This uptake placed physical education as the $14^{\text {th }}$ most popular A level out of the reported 35 individual subjects on offer (Joint Council for Qualifications, 2011). Such was the proliferation of schools offering examination physical education that Reid (1996a, b) was prompted to suggest that examination teaching had become the 'new orthodoxy' of the subject. A decade later, Green (2005) and Thorburn (2007) both supported this claim, suggesting that examination teaching now holds a dominant place in both the national discourse and in the lives and careers of many teachers in the UK.

A similar discourse emerged at a state level in Australia. Fitzclarence and Tinning (1990) argued that in the early to mid 1970s the idea of physical education as an examinable subject in the final year of schooling would have been considered ludicrous. These authors argued that the original purpose of examinations was to screen students with respect to university entry, and in such a process there was no place for a practical subject focused on games and sport rather than academic pursuits. However, there was growing resistance to the use of matriculation examination as the sole arbitrator of schooling success and alternative subjects, including physical education, were included as examinable subjects. The rise of Colleges of Advanced Education, the diversification of the higher education offering and the acceptance of students from 'alternative' educational backgrounds paved the way for the emergence of physical education as a popular examination subject (Fitzclarence and Tinning, 
1990). The development of examination physical education as a new orthodoxy for teachers in Australia, is further highlighted through the uptake by students at state level. The Board of Studies in New South Wales (NSW) (2001), for example, reported that 9417 students took Personal Development, Health and Physical Education as a Higher Schools Certificate (HSC) in the year 2000. By 2010 this number had risen to 14283, placing the subject behind only Biology, Business Studies, Mathematics and English on the list of most popular subjects taken as a HSC in NSW.

However, despite proliferation of accredited qualifications in physical education in many countries, and the argument that this had lead to a new teaching orthodoxy, there is little research that investigates the actual process of teaching. The purpose of this paper is thus to explore how pedagogical change in examination physical education was experienced by, and impacted on, pupils and teachers in one school during a year long unit of the Oxford, Cambridge and RSA Examination Board’s (OCR) Advanced Subsidiary Level (AS Level) physiology and anatomy. However, in order to explore the dominant practices within examination physical education it is important to understand more about the emergence of physical education as an examination subject. The academicization of physical education and its quest for legitimacy is especially important given the suspicion that Macdonald and Brooker (1999) felt is levelled at performance-oriented subject in schools (such as art, music, drama or physical education) when they seek to be seen as something "of educative worth” (p. 171).

\section{The academicization and legitimatization of physical education}

In the late 1950s in the USA, physical education faced a crisis of identity (Choi, 1992). In light of American education’s ‘humpty-dumpty-like’ fall from innocence following the launch of Sputnik in October 1957 (Tinning, 2009) physical education 
was accused of representing all that was bad about educational practice (Conant, 1963) and threatened with the cancellation of all its graduate programmes (Choi, 1992).

If I wished to portray the education of teachers in the worst terms, I should quote from the description of some graduate courses in physical education. To my mind, a university should cancel graduate programs in this area. (Conant, 1963, p. 201)

Emerging from this condemnation was a piece of legislation requiring physical education in all university departments in the US to either have an academic basis or cease to be considered as a university-level subject. According to Rose (1986, p. 8) this led to a search for an academic discipline of physical education based on "the art and science of human movement”. Subsequently, the response to this very real threat of extinction was the emergence of kinesiology in a number of US universities with sport pedagogy as a sub-discipline (Henry, 1964).

In his work around curriculum change Goodson $(1981,1993)$ offers an insight into the relationship between subject developments in higher education and in school subjects, maintaining that 'the direct connection between ' $O$ ' and ' $A$ ' level examinations and the academic tradition is one of the most enduring features of our education system” (Goodson, 1993, p. 24). Indeed Goodson (1981) suggest that the obsequience of teachers to academic knowledge was perceived as a pathway to gaining higher status. Although, the academicization of physical education in universities (Green, 2005) was not replicated in American schools, where physical education has remained as a practical subject that is assessed predominantly though student performance, Penney and Evans (2013) recently argued that both the standing and academic status of physical education has in all probability been raised as a consequence of the development of examination courses.

The move towards the academicization of physical education, celebrated by many physical educators, seems in keeping with what leading social critics such as 
Apple, Ball and Levin maintain is a move towards one version of schooling synonymous with the globalisation of educational policy. Indeed, when the combined work of a number of authors is read in conjunction with one another (Brown \& Penney, 2013; Green, 2005; MacPhail, 2004; Penney et al, 2012; Thorburn, 2007, Thorburn \& Collins, 2003; Thornburn, Carse, Jess \& Atencio, 2011) it seems that the similarities of physical education examination practices across countries might considerably outweigh the differences. Through this commonality of practice we have witnessed that verbal or written examinations are firmly positioned as the preferred means of assessment, in contrast to the emphasis in the gym remaining on the performance of physical skills. In this positioning the separation of 'theory' and 'practical' forms of knowledge is maintained. For example Fitzclarence and Tinning (1990) reported that the Australian HSC “virtually excluded all physical activity” echoing "the pedagogy of high status academic subjects” (p.177) and highlight the trend to define examination physical education in "increasingly narrow and fragmented ways” (p.181).

Although curricula exist which attempt to integrate theory and practice, such as the HSPE in Scotland which integrates practical expertise and analysis of performance with written forms of expression used to record attainment in such analysis, Thorburn and Collins (2003) highlight that the challenges of the curriculum have limited the pedagogies of those that teach it. Similarly Brown and Penny (2013) suggest that although the Victorian Certificate of Education in Physical Education integrates theoretical and practical elements, the course content reflects the "“official’ theoretical/academic discourses” (p.47) that give it legitimacy within the curriculum and the practical activity have not received comparable status, particularly in relation to assessment. Indeed, Wright (2000) argues that attempts to justify its value "on the 
same criteria appropriate for an academic subject” (p.273) distort the nature of physical education.

In her research on teachers’ perceptions of externally prescribed physical education examinations in Scotland, MacPhail (2004) found that many teachers felt that they (and their departments) were well positioned to teach examination physical education for a number of reasons. These included firstly, that they were interested in teaching at this level and believed that they would be successful in gaining high grades for their students. Secondly, they also believed that they had sufficient expertise with respect to the teaching of examination physical education. From these outcomes MacPhail $(2004,66)$ reported that teachers “admitted that the more attractive feature of the introduction of examinable physical education [as opposed to addressing pupils' needs] was the rising of their own status.” Interestingly the conviction that physical educators have sufficient expertise to teach examination physical education contrasts with concerns about the practical subject content knowledge of neophyte physical educators (Siedentop, 2002). While recognising the changing composition of PETE courses, which we discuss in the next section, questions remain about physical educators expertise in examination physical education given the overall reduction in undergraduate contact hours in PETE programmes (Lee, O’Donovan, Choi and Kirk, 2012).

\section{Knowledge base for examination physical education}

In considering a landscape dominated by the academicization of physical education in universities in the US, Siedentop (2002) argued that as a consequence of physical education's rapid reconceptualization as an academic subject, the practitioner was being increasingly stripped of the basic content knowledge needed to teach practical physical education lessons. Drawing on the work of a number of academics, 
including Shulman (1986), Vickers (1987) and Hoffman (1987), Siedentop argued that while there had been a considerable increase in pre-service teachers' knowledge of pedagogy in the form of methods, processes and procedures, this was at the expense of the subject matter of practical school physical education. Siedentop (2002) concluded that while a return to the days of courses focusing on practical skills was not the solution, student teachers and coaches did need to understand pedagogy both theoretically and as performers. In other words they needed to greatly enhance their practical subject matter content knowledge.

In his meditation on the future of physical education, Kirk (2010) argued that the dominant and change-resistant form of the subject (i.e. multi-activity, sport-based lessons) has led to a construction of learning that is out of kilter with the needs of the $21^{\text {st }}$ Century. Kirk also suggested, in keeping with the arguments of Siedentop (2002), that the academicization of the subject at university-level has led to a form of physical education teacher education that has seen a "reduction and marginalisation of the experience of practical physical activity [which in turn] has produced teachers better suited to teaching senior high school examination versions of physical education than the core programmes for younger pupils” (Kirk 2010, 137).

Similarly Tinning (2002) concurred with the arguments of Siedentop (2002) that the subject matter content knowledge of physical education needed to be both practical and theoretical. However, drawing on the work of Alexander (1987), Tinning (2002, 380) argued “pedagogical content knowledge for theoretical subject matter is only covered indirectly in the process of teaching other courses”. In other words, while PETE students may know more about the theories of kinesiology when they came to teach them in schools, they may not have had the pedagogical know how to be successful. Consequently, although MacPhail (2004) held that teachers perceived they 
had sufficient expertise to teach examination physical education, and Siedentop (2002) and Kirk (2010) have both argued that physical education theory has been privileged over practice, is there a gap in teachers’ pedagogical ability to teach examination physical education?

\section{Methods}

\section{Context, participants and intervention}

This project took place in a physical education department in a comprehensive school in the South East of England. The impetus for the selection of this site was that the head of physical education and a teacher were seeking advice on how to improve their teaching of high stakes examination classes and in consequence contacted the first author. The staff wanted to explore and subsequently change their teaching of the Anatomy and Physiology (Anat and Phys or A and P) component of the AS physical education examination and adopt a new method of teaching this course across a school year. The specific participants were the head of department (HoD) ('David' pseudonym) and the Anatomy and Physiology teacher ('Nigel'), and all five students who were taking AS Physical Education in the school. The result of a number of meetings was the co-construction of a new approach to teaching this module, based around the Cooperative Learning model and the use of a web-based wiki.

\section{The Anatomy and Physiology Unit}

The department followed the OCR Specification for AS and A level Physical education. As Table 1 shows, Anatomy and Physiology (section A) was assessed as one of three parts of the unit 'an Introduction to Physical Education'. This unit was assessed through a two-hour written examination, worth $60 \%$ of the overall AS 
qualification. This exam was externally set, marked and moderated, and the Anatomy and Physiology section constituted $20 \%$ of the final AS mark.

[Insert table 1 about here]

Nigel taught these students weekly during the year-long Anatomy and Physiology unit. His teaching focused on the use of Cooperative Learning structures such as 'pair-check-perform’, 'I do, we do’, and ‘learning teams’ (Dyson and Casey, 2012). No classroom observations of teaching were undertaken, and therefore there is no way of discerning how these structures were used. As a consequence, these interventions are described as collaborative. The wiki was used as a platform for the students and teacher to place materials, interact with one another and ask questions. Its initial purpose was to expand the classroom and offer an innovative teaching and learning experience that was beyond the traditional boundaries of schooling.

\section{Data Gathering}

Prior to the start of the study ethical consent was sought and subsequently granted by university’s ethics committee, and assent was gained from all the participants for their involvement. All interviews were conducted by the first author, were recorded on a digital voice recorder and later transcribed verbatim. The teacher interviews occurred in the staffroom, and the student interviews took place in one of the school's classrooms.

David was initially interviewed on his own in his capacity as HOD. This interview formed an integral part of an initial 'brainstorming' of ideas around change within the department's teaching of examination physical education. Once a class and a teacher had been identified David and Nigel were interviewed together, and prior to the start of the academic year, to explore their shared expectations around changing practice in examination teaching. Nigel and the five students were also interviewed 
towards the end of the school year, but before the examination was taken. Finally, an exit interview was conducted with Nigel at the start of the next academic year at a time when he was preparing to teach the A Level course and when he had time to reflect on the examination results. Secondary documents, including the wiki, the departmental policies, schemes of work and the exam board specifications also form part of the data.

\section{Data Analysis}

Our analysis involved three key steps. Firstly the text from the different data sources was coded independently by each author (Corbin \& Strauss, 2008). We each read the different components of the data and recorded instances where critical incidents and experiences occurred in the data, such as the disparity the teachers saw between their practical and theoretical teaching. Secondly, we compared our coded data and sought to identify where similar and contrasting incidents etc. had occurred. With our independently coded data, we shared the instances we had identified that we felt were significant. Each example was shared, and then questioned and critiqued by the other author in an attempt to ensure that we were in agreement as to its significance. This led to the development of a number of tentative themes: A Level Theory - missing the grade; How to teach theory?; Anticipating Change; Impact of the intervention; Defining a good lesson - the pupils' perspective; and Where is the 'physical' in A Level Physical Education?

The third step of analysis involved re-coding the data according to these initial themes. However, the principles of constant comparison (Corbin \& Strauss, 2008) suggest that data be continually coded and re-coded until a level of theoretical saturation is reached. Following several readings of the re-coded data we found that our results could be best represented by two themes, and their associated subthemes. 'Missing the grade' explores the issues Nigel and David identified and is organised 
around three key subthemes of student performance, theoretical content knowledge and teachers' pedagogies. The second theme explores the impact of the intervention, and is organised under two subthemes: learning new pedagogies and transferability, and pupil experience of change.

\section{Results and Discussion}

In the following section we will start by exploring the reasons and justifications given by David and Nigel for choosing to change their teaching of anatomy and physiology. When asked what inspired the department to choose to develop a new approach to teaching, focused around the Cooperative Learning model, Nigel responded:

I think it was two things, it was identifying why pupils weren't doing so well in this area, [and] identifying the fact that it might have been the way we were delivering some of the content (Nigel, pre-examination interview)

\section{Missing the grade}

\section{Student performance}

The significant factor in this project was the honest endeavour, on the part of the department and the two teachers involved, to change their teaching in response to what they saw as the underachievement of their pupils. David and Nigel believed that the overall grades for examination physical education had been problematic for the department. Within their teaching of the wider specifications, Anatomy and Physiology was singled out as the area that most negatively impacted on overall grades as students 'struggled with the exam'. Both Nigel and David, in his capacity as HoD, commented on this in their pre-research interview that:

A and P traditionally has been one of the areas, the anatomy and physiology, where they've really struggled with the exam and it's pulled down their overall grades. (Nigel, pre-intervention interview with David)

They're getting grades but they're not the top end grades and it's that element that's letting them down and we've got some top students, we've got some good students practically, they do work hard but it's anat and phys that really does 
seem a hurdle and I think that's where we've got to focus... (David, initial interview)

In both the metaphor and the reality of moving in from the 'cold' of gymnasium and playing field and into the 'warmth' of the classroom, and in transforming the subject from a practical to a theoretical one, the staff clearly identify that their 'good students practically' (i.e. those who were able performers) are failing to achieve at comparable levels in anatomy and physiology. Given the belief that it was not because these students did not 'work hard', it seems inevitable that staff were in agreement that this subject area necessitated development. The teachers felt that the problems the school faced in relation to anatomy and physiology were longstanding issues, and as a consequence David, in his initial interview, highlights the staff's arrival at 'that stage' of considering change:

I know there's a massive problem the students have with the anat and phys, without any question and that's historical and it's getting to that stage now of how can we start to get over that hurdle for the students to do better?

Although MacPhail (2004) highlighted teachers’ personal motives in advocating for and embracing examination physical education, it is clear that student performance remained at the heart of staff motivation for change. Furthermore, it is important to note that they did not believe that the issue was unique to their school as analysis by the department highlighted a similar trend across the county.

there's not many [other schools] there who are hitting where they should be hitting, so when you look at it in that context, there's obviously an issue with either how A Levels are delivered or this mismatch of the content and what we are trying to get from it. (David, pre-intervention interview with Nigel)

Their concerns about the success of their pupils, and that of pupils across the county, resulted in some introspection from Nigel and David about their own performances in teaching examinable physical education; particularly given that they identified their own students as 'good students practically' who ‘work hard'. Indeed it 
could be argued that the teachers themselves felt that they were possibly also missing the grade, an issue to which we will now turn.

\section{Theoretical Content Knowledge}

Over the last three decades we have witnessed physical education teacher education programmes reduce their overall contact hours in the UK, USA, Australia and Korea (see Lee et al., 2012). Although much has been written about the impact of reducing hours in practical content knowledge and the privileging of discipline knowledge over practical content knowledge in PETE programmes (see our previous discussion), given the overall reduction in hours for PETE courses we have not witnessed a simultaneous increase in discipline knowledge, theoretical content knowledge or pedagogical content knowledge for examination physical education despite the growth of examination physical education (Lee, et al., 2012). In his initial interview David identified that the anatomy and physiology content knowledge necessary to teach A and AS level physical education "frightens people" as "one of the harder bits of the teaching job”.

I find a lot of it difficult...in terms of functions of muscles or it's that kind of 'nitty gritty' that throws the students and throws me, you've got to get into it and read through it and know...

The belief that teachers find this aspect of teaching particularly difficult contrasts markedly with the arguments made by Siedentop (2002) and Kirk (2010). Both of these authors contend that discipline knowledge is privileged over practical knowledge in contemporary physical education programmes. Indeed, this finding links with the work of MacPhail (2004) who established that teachers believed that they had sufficient expertise to teach examination physical education and would be successful at doing so. In contrast Thorburn and Collins (2003, p. 191) were concerned about the “quality of teaching approaches adopted in examinations in PE”. These authors further 
argued that too many practitioners resorted to worksheets and "talk and chalk" approaches in the classroom. The teachers in this study recognised the content area of anatomy and physiology to be the most challenging and the one where they had the least perceived expertise, particularly when contrasted with their teaching of practical physical education, where they described their approaches with confidence. That the teachers believe that there is an issue with the results in this area of the curriculum across their county, does question the extent to which perhaps teachers' fail to give due consideration to what 'sufficient expertise’ might entailed. Indeed, overwhelming personal motives for introducing examination physical education, and the desire for the legitimisation of physical education among other curriculum subjects, may previously have impeded their judgement when it comes to what they need to know to successfully teach theory lessons.

\section{Pedagogical practice}

Although acknowledging some concerns about their own theoretical content knowledge, David also had concerns about the pedagogies utilised in examination physical education.

...The guy we used to have was exceptionally knowledgeable but his delivery style was not good, it was stand at the front, lecture and I think that's what lost some of our students...he was just like a sponge but he regurgitated it in a way that you needed to understand and have a background knowledge in it, I went into lessons and literally students were starting to fall asleep, glazed over (David, initial interview)

As David illustrated here, even when theoretical content knowledge was perceived as being 'exceptional', pedagogies that supported student learning in examination physical education remained problematic. Indeed David identified that the good pedagogical practice used in practical physical education was often not transferred to the classroom and was an issue on which they were working: "that's the one thing that we, I think, we're good at in the practical PE and we're working towards 
becoming a lot better in the classroom”. The pedagogies of practical physical education described by the teachers, embedded independent learning, group work and peer learning, were recognised by staff as areas of weakness in the classroom.

I think it's how can they learn by themselves as well and I think that's what our students find difficult, is that research element, they find it difficult to go away and even if you give them quite a searching question, they find it difficult to research it, so that I think is where we're coming from. (David, pre-intervention interview with Nigel)

Notwithstanding these criticisms of their own approach, the teachers' recognised that they have 'tried things in the past' with some success, drawing into the classroom the pedagogical strengths they recognise from 'practical' physical education. Indeed, one of the core motivations for this study was that the teachers were not happy with this state of affairs. However, in keeping with the work Thorburn et al (2011) and in an effort to overcome what they perceived as a gap between their practical and theoretical knowledge, David and Nigel were "motivated and committed to improving the quality of physical education” (p. 321).

Previously, I always have tried to use a variety of different teaching styles and not just dictating to them and getting them to copy down things off the board or copy slides or work from worksheets, so I have tried things in the past such as small group work, pairs work, peer assessment, peer analysis work (Nigel, preexamination interview)

In addition to the planned collaborative learning changes, technology was a second element that they sought to develop as part of this intervention. They particularly felt that they did not utilise Information and Communication Technology (ICT) well to enhance student learning. Although ICT was already being used, it had simply been incorporated into their didactic approaches to classroom lessons. As a consequence PowerPoint had merely replaced the blackboard or whiteboard and was now acting as “an extension of what you were writing on the board” that is "all nice and shiny”. David, in the pre-unit interview with Nigel commented that they have 
“tried to move away from PowerPoint... all we're doing is spoon feeding them the information.” Their experiences of limited teaching styles and strategies for theory lessons do not appear to be unusual. Indeed, Bowes (2010) highlights that in New Zealand senior school physical education lessons in many classrooms appear to be dominated by note taking from theoretical Power point presentations and completing workbooks.

Clearly student engagement in the learning process was central to the 'change agenda’. The staff felt that the modern student was already engaging with technology and therefore the staff highlighted that they wanted technology to be integral in the improvements they were seeking to make. The adoption of a wiki was viewed as supportive of their goal to engage students through web-based technologies.

the wiki for us is [great as it gives] the students great ownership of it [the classroom] and I think that's the important bit for us, the students having ownership of the learning (Nigel, pre-examination interview)

This decision was further legitimised by their perception of the external pressure from OfSTED ${ }^{\mathrm{ii}}$ to engage in less didactic approaches, which had already acted as a stimulus for the work they had begun.

We're already making strides in that because of OfSTED and the way that learning's developing, they are now looking at not the member of staff, they're looking at the students and if you still teach from the front of the class, the students aren't engaged, so we're moving away from that didactic approach. (David in the pre-unit interview with Nigel)

The aspiration to change the way examination physical education was taught was clear. However, it is unsurprising that the prospect of transforming the pedagogical practices of classroom physical education teachers would be greeted with a mixture of trepidation and optimism. Despite David’s assertion in his initial interview "I want to move the way that learning is moving and it's really important....”, he also acknowledged that some of the other teachers in his department were reluctant: 
Some of the team are still struggling with it, can't deal without being, "this is what I'm doing, I'm going to read something out”, chalk and talk, no, get away from it.

Perhaps this reluctance could be anticipated given that in many Physical Education Teacher Education (PETE) programmes in the UK and elsewhere, neophyte physical educators receive little professional preparation for teaching theoretical lessons (Lee et al, 2012; Tinning, 2002). Clearly the HoD in this school highlighted a fundamental desire to examine and improve teachers' range of teaching styles for the delivery of anatomy and physiology. The congruence between the problems identified by David and the perceived priorities of OfSTED in terms of innovative pedagogies, student engagement and student achievement, although unsurprising, were central to the legitimisation of change and the process of planning for change.

Furthermore, David highlighted that this was on top of a broader range of ‘responsibilities’ expected of the modern physical education teacher.

[schools are] expecting us to do GCSE ${ }^{\text {iii }}$, to do BTEC ${ }^{\text {iv }}$, to do national certificates in sports, key stage 4, key stage 5, A'Levels...we're spending all our time marking, assessing and inputting data and then you want us to do house matches, fixtures, clubs...these guys [other PE teachers] are saying...hang on a minute...where's my time...what you want to be doing is giving kids every opportunity but now you've got to find strategies and ways around it...

Such expectation - which melded the traditional extra-curricular expectations and the "new orthodoxy" of physical education - has ramifications for teachers' potential to engage in innovative practice.

Notwithstanding the key areas identified for change and teachers' workload, the significance of the high stakes examination was undiminished - both for the students and the teachers. The importance of the examination results, within the culture of schools themselves is unquestionable, and regardless of the efforts made within this department, the importance of innovative pedagogical approaches was secondary to the 
outcome on results day. The teachers acknowledged and underlined the inevitability of the final exam in planning for change.

...we've still got to hit the focus of- they've ultimately got to sit in an exam hall and do the paper. (David, in the pre-unit interview with Nigel)

\section{Impact of intervention}

\section{Pedagogical approaches}

The second theme in the results explores the perceived impact of the intervention just prior to the 'sitting' of the examination and following the release of the examination results. In interviewing the teachers again following the anatomy and physiology teaching, the staff highlighted the personal challenges of changing their classroom pedagogies to embrace collaborative learning and the wiki.

...it seems that in some ways I'm a lot less active in the lessons and taking a bit more of a setback role [a background role], once they're on task and engaged and they know what they're doing, then it's more of a step back and intervene only at certain points in the lesson or when they're doing a certain task, so in that sense it does seem to me that you're doing a lot less teaching and teacher involvement with them. (Nigel, pre-examination interview)

Nigel's changing of role, from teller to facilitator, is in keeping with findings from the Cooperative Learning literature (Dyson and Casey, 2012). Furthermore, Nigel highlighted that the approach took time to embed and that they (both the students and him) had to be adaptable in their respective roles (both as teachers and learners). This was not easy and it took a while for the students to get use to it.

...the idea of trying to use collaborative learning with them, I think so far it has been something they have enjoyed, it's something new so to start off with it did take a bit of a while for them to get used to it... (Nigel, pre-examination interview)

Given the literature around curriculum change through the use of Cooperative Learning in physical education these patterns of engagement were predictable. In work in Cooperative Learning Dyson (2001, 2002) and Dyson, Linehan and Hastie (2010) have written about the time needed to learn how to teach through the approach. 
Similarly, in his review of literature around teachers' use of models-based practice in physical education Casey (2012) argued that in using any pedagogical model not only do teachers have to learn to teach in a new way, but students also need to learn how to learn in a new way. This notion of learning a new approach was picked up on by Nigel:

there were a couple of things when we first started that, that they did find it a different approach but I think they're now at the stage where they know what we're doing, they know why we're doing it and it seems to be fairly successful at the moment (pre-examination interview)

Similarly, the students identified that the pedagogical approach used in this unit was very different to that used in their other examination subjects, which they described as predominantly individually focused:

Interviewer: Can you make a comparison between your AS Physical Education lessons and your other experiences of examination classes?

Jenny: We use quite a lot of collaborative learning within PE whereas within other lessons we don't use it as much, to come together as a group to learn more about the different styles.

Interviewer: How would you describe the other classes?

Jenny: They're more independent learning, they're more independent subjects whereas in the games situations, you have to work as part of a team.

Interviewer: So these are collaborative and cooperative but the other ones are individualistic?

Jenny: Yes, quite a bit, the other ones are quite independent but you do do some collaborative learning but in PE you mainly use collaborative.

Interestingly although the students described few practical activities they engaged with during this unit, they continued to make the connection with physical education in games situations where "you have to work as part of a team”. Although recognising that collaborative learning is a feature of other lessons, they describe that they "mainly use collaborative" in Anatomy and Physiology, identifying strongly with this element of the unit. Similarly Nigel mentioned the important role of tasks in the revamped unit with technology supporting the implementation.

...having the tasks planned in advance and having them linked into what we're doing in terms of what area of the syllabus we're looking at, that helps to make 
the task flow, to get them engaged, so having a good plan, having it well laid out, focusing on certain areas...Yes, on reflection I'd probably say that I am spending the majority of the time pre-lesson planning, making sure the resources are there and it's set up ready to go. (Pre-examination interview)

The ‘setback' or backstage role Nigel said he played during lesson time seemed to facilitate student engagement. Nigel highlighted that pupils had increased time to 'get on' with the tasks and thus increase their engagement.

it's less talking, still getting involved with the lesson in terms of answering questions, Q\&A, jumping in at certain points but in terms of less talking in the lesson, less explanation, for time for pupils to get on with something and be engaged. (Pre-examination interview)

Likewise, the students also identified "getting involved" as a key feature that differentiated physical education from other examination classes. Jack refers to “getting involved” or "getting proper involved” multiple times, contrasting this with “just writing stuff down” and doing it “just by yourself” in other lessons.

Interviewer: Can you make a comparison between your AS Physical Education lessons and your other experiences of examination classes?

Jack: We do quite a lot of exercise, getting involved in stuff rather than just writing stuff down all the time and cutting stuff and that, getting proper involved in stuff and working in groups and that...I can't explain it, it's not just like writing stuff down all the time, it's getting involved and doing activities and exercises together as a group and stuff, rather than just by yourself.

In determining the success of this unit, the staff hoped that increased student engagement, as Jack describes above, would equate with improved exam results. In one respect the increased engagement was certainly seen by the students as a positive of the subject. Jenny commented as a class they worked both in groups and individually to help them learn more. Furthermore, both Thomas and Jenny said that the interactive nature of the wiki played a role in facilitating their learning:

Jenny: Yes, in PE we do some working groups and some work individually to help us learn more.

Interviewer: Do you find it an interactive space or somewhere you just kind of get information from or put information? 
Thomas: Interactive space, we don't just put, it's sort of everyone working together so you can use it in class as I've said and use it if you want to revise and that.

Through the use of the Wiki Nigel was able to track who was engaging with and contributing to the development of shared knowledge on the Wiki.

Interviewer: the technology, is that a useful tool?

Nigel: Definitely, yes, having the technology can only really help their learning, it's something that they benefit from and it helps their learning to improve.

Interviewer: Do you think it's a meaningful use of technology?

Nigel: Yes, definitely, it's something that for a lot of them, they're new to as well, it's something that they haven't necessarily used before so there's that whole idea of this is new, this is quite exciting, quite interesting.... with the WIKI page, I can see who's been on there, who's accessed it, what they've contributed to the page, what their input is so that's a definite benefit to it.

(Pre-examination interview)

\section{Student enjoyment}

Oscar: certain teachers I'd say, certain teachers teach in different ways I think. Like some teachers are happy to talk for most of the lesson and then leave note taking and things like that to out of the classroom, and some prefer to get more work done in the lesson, make sure we understand, do notes and things in the lesson.

Interviewer: Would PE be an example of the good or...?

Oscar: Yes, would definitely be an example of the good compared to my other subjects, I definitely prefer the way we learn there, yes.

Despite the students' positivity in relation to the approach, when asked what a good lesson looked like, they described good pedagogical practice in very traditional terms making reference to variety in individual and group work and the importance of having a good beginning with developments, and activities or tasks.

Jack: I'd get a good start to get us all involved and that and then maybe work in, write something down and then going over it at the end again, seeing what we've done and then any questions and that, like to work it out.

Moreover, the novelty of the approach seems to have facilitated their enjoyment as Simon later commented that "it was a different way of doing it, it's better than the usual I suppose because it’s something different.” While students highlighted that the novelty was a factor in their positivity, it is interesting that they continued describing 
this unit as different after nearly a full school year of implementation, a length of time after which it would have been expected that the innovation would have been normalised within the school, no longer being described as 'different'. Furthermore, the pupils' perception of the uniqueness of this approach may have been in its difference to other examination subjects' pedagogical approaches that they were used to in school.

Simon: In AS PE it's more of a relaxed atmosphere and even though we get through the work, we get through the work and we do different activities in order to get through the work.

Interviewer: So what sort of things are you doing that's different or PE or the same?

Simon: There's more group work I'd say and it's just ... I don't know, it's different, it's just a more relaxed atmosphere.

Nigel indicated that potentially boredom with the teacher and didactic teaching style utilised previously had played a role with disengagement and lack of enjoyment.

they're not bored with us, I think again that's something we're trying to get over to them, is so many more places that you can learn apart from us being with you. (Nigel, pre-examination interview)

\section{Exam Focused teaching}

Although student enjoyment and engagement in the unit were important, the teachers highlighted throughout that ultimately the exam results were central to their decision to attempt to improve practice. Students commented that the wiki supported the exam specific work such as “creating exam questions and answers”, to "help us revise" (Simon), "to do the exam questions" (Thomas) and go "through the marking scheme” (Thomas). The students’ comments highlight the independence they had from their teacher in this revision process

Thomas: With these classes we do more group work together, making booklets for revision for exams and use other stuff like WIKI pages and virtual learning environments to help us revise more, got past papers and other stuff on there for us to use ourselves, to help us revise. 
The students also found that using the wiki to mark others' work was particularly beneficial in ensuring that they knew "the information" themselves "in order to mark it”.

Simon: When we do homework on the WIKI, the teacher got it up at the front and showed us and we had to mark each other's work, so we went onto the WIKI and marked someone else's work.

Interviewer: I'm interested in how you found marking, did you learn from marking somebody else's work?

Simon: Yes you did because you had to know the information yourself in order to mark it.

Thomas commented that he found the process of going through the exam questions and markings schemes not only beneficial in terms of learning but also enjoyable. This was particularly true as the exams approached and took on more significance in their lives.

Thomas: I use it in class to do the exam questions and going through the marking scheme to see what the examiner would have put. I think that's enjoyable and also we've got information that we can use and make into little booklets, so we can use them as well because I think that helps us learn better as well...We've used it more and more as the year's gone on .... as we've progressed through the course, we've been using it more because more information's being put on there for us to use and we'll use it more towards the exams as well, so it's building up and building up as the year goes on.

Similarly, Nigel indicated that students' attainment was improving gradually in 'mini snap tests' with the hope that this would translate into final results:

this approach...is helping them so some of the tests that we have done, some of the mini snap tests that we have done has shown that their grades have been quite good so what they're taking in the information, they are learning something so far and hopefully that will be reflected in their summer exam results. (Preexamination interview)

At the exit interview Nigel highlighted that some students had, in the department's opinion, overachieved while some underachieved in the final exam relative to their predicted grades. When questioned about what this meant Nigel went on to explain: 
Nigel: with setting their target grades, we would have based that on what they did at GCSE and some of them did exceed that and did do better...

Interviewer: Do you usually get your target grades right or is there normally an overachievement by some and an underachievement by others?

Nigel: In general they are usually there or there about- but probably usually an underachievement in terms of target grades. (Nigel, pre-examination interview)

Although not all students achieved results in line with their GCSE grades, this 'underachievement' has traditionally been a feature of examination physical education at the school, and indeed was the stimulus for this intervention. That some students overachieved in this academic year was deemed a success by the department. The perceived success of the intervention, in terms of student engagement, learning and examination results, prompted the department to develop these pedagogical approaches to their other examination classes including GCSE and A level classes and indeed into other subject area.

Some of them have achieved well over the course this year and this is something we want to carry on with the methods we are using into their second year...having done it and seen the success of it and how it has helped the students it is something that we will want to roll out across other subjects, GCSE and A level and maybe into other subjects across the school. (Nigel, exit interview)

Given the high stakes nature of examination physical education, the final results for the subject were of particular significance to the teachers in terms of assessing the impact of the intervention. However, that student enjoyment, engagement and responsibility for their learning also improved alongside the results was significant in the teachers' decisions to extend this approach with other groups.

\section{Conclusions}

Reid (1984), Williams (1985) and later Kirk (1998) and MacPhail (2004) all contended that innovation in physical education could only occur if it matched "the interests and understanding of various legitimating publics” (Kirk 1998, 109). The 'publics' in this study were the predominantly the staff and students who taught and 
took AS physical education. However, a secondary population - the school’s leadership team (who are responsible for raising overall examinations results), OfSTED (who inspect teaching and learning) and the students' parents and carers (who have concerns with regards to the results each respective student achieved) - also need to be considered as having an investment in the teaching that occurs in these classrooms. That the teachers perceived that overall results were improved using this approach is a positive but is there a point at which the teachers' ability to innovate is restricted by their theoretical content knowledge, their pedagogical content knowledge for examination physical education and the new orthodoxy of teaching in physical education?

In this study student engagement and achievement were highlighted as focal issues, which the teachers wanted to improve by changing their pedagogical approach to examination physical education. Consideration of what David call their existing “chalk and talk” pedagogies revealed concerns about how this didactic approach might “pull down” their students’ ability to get the best grades in examination physical education. Yet their practices do not seem unusual. Reid (1996a, b) argued that physical education underwent a radical change of identity in redefining itself as an academic subject in the school curriculum, and consequently replaced much of the familiar teaching and learning practices of physical education with classroom alternatives. Indeed, Culpan, Draper and Stevens (2011) reinforce Hendry's (1996) argument that teachers in training may have to undergo a conceptual revolution if they are going to teach exercise sciences in physical education in a manner that promotes the notion of learners establishing and drawing interrelationships between content, students' and their environment. Examining pedagogical approaches to the teaching of exercise sciences at University, Culpan et al (2011) highlight that lecturing staff in 
three Universities use an eclectic approach to pedagogy that is dominated by lecturerled and dependent styles and a reluctance to employ constructive styles. Although we acknowledge that pedagogical content knowledge is underpinned by content knowledge, we question the extent to which physical educators have witnessed appropriate pedagogies for the teaching of theoretical content knowledge in secondary schools during their teacher education programmes.

Despite the pedagogical strengths that David saw in his department's teaching of practical physical education i.e. in group work and task based lessons, it was apparent that he was frustrated with the uni-dimensional pedagogies that dominate the teaching of AS anatomy and physiology. Indeed this contrasted with the descriptions of teaching styles in practical lessons and it seems that, in positioning physical education as a legitimate sibling of other academic subjects, the physical educators dismissed the pedagogical approaches that worked well in practical physical education lessons and instead embraced a traditional approach to teaching pupils in classrooms.

As a consequence of this year-long intervention pupils reported that physical education lessons during this unit were 'very different', 'enjoyable' and 'more relaxed'. Higher engagement levels, increasing independence and improved focus on the exam questions and marking criteria were also noted, as was the department's determination to take this approach forward and broaden its use in the teaching of other examination subjects. Despite the success of this unit, the question remains. In seeking legitimization, has the physical education community embraced a new teaching orthodoxy for which it is ill-prepared to teach? Indeed, in the drive to overcome a 'double dose of marginality’ from the school curriculum and the wider sports community it might be argued that we are yet to really notice the change. Perhaps it was assumed that the increased academicization of our undergraduate and postgraduate 
PETE course was, as Kirk (2010) argued, already better at preparing our graduates to teach the various examination versions of physical education. However, it seems that the key idea of 'how' to teach these courses - i.e. the teachers' theoretical pedagogical content knowledge - seems a significant omission in an era where examination physical education remains on the ascendency.

While it has been so vehemently argued that PETE programmes need to better prepare teachers to be teachers (Siedentop, 2002) this paper now positions pedagogical content knowledge for theory lessons as an area for consideration. The assumption has been that the academicization of physical education has implicitly prepared teachers to teach the high stakes examination that have begun to dominate their daily lives. Yet, as this paper suggests, knowing 'what' to teach is not sufficient. The 'how' and the 'why' of theoretical knowledge now need to come increasingly to the fore in PETE programmes if physical education teachers are to be best placed to come in from the cold and be accepted as legitimate subject specialists of equal standing to their peers. 


\section{References}

Alexander, K. 1987. What your method lecturer should have told you. ACHPER National Journal, 117: 23-26.

$\mathrm{Au}, \mathrm{W}$. 2011. Teaching under the new Taylorism: high-stakes testing and the standardization of the 21st Century curriculum, Journal of Curriculum Studies, 43 no. 1: 25-45.

Board of Studies New South Wales, 2012. 2011 HSC Student Entries by Sex (accessed $1 / 12 / 2012$ at $22.23 \mathrm{pm}$ ) http://www.boardofstudies.nsw.edu.au/ebos/static/EN_SX_2011_12.html

Board of Studies New South Wales. 2003. HSC assessment in a standards-referenced framework: a guide to best practice. Sydney, Australia: Board of Studies NSW.

Board of Studies New South Wales 2001. 2000 Higher School Certificate, Examination Statistics. Sydney, Australia: Board of Studies NSW (accessed $1 / 12 / 12$ at 22.10pm) http://www.boardofstudies.nsw.edu.au/bos_stats/pdf_doc/hsc00_statistics.pdf

Bowes, M. 2010. Teaching as inquiry: What has influenced the development of senior school physical education in New Zealand? Journal of physical education New Zealand, 43 no. 2: 20-24.

Brown, T. D., and D. Penney. 2013. Learning 'in', 'through' and 'about' movement in senior physical education? The new Victorian Certificate of Education Physical Education. European Physical Education Review. 19: 39-61.

Carroll, B. 1994. Assessment in Physical Education: A Teacher's guide to the issues. London: Falmer Press.

Casey, A. 2012. Models-based practice: great white hope or white elephant?, Physical Education and Sport Pedagogy, DOI:10.1080/17408989.2012.726977

Choi, E. 1992. Beyond Positivist Sport Pedagogy: Developing a Multidimensional, Multiparadigmatic Perspective. University of Georgia

Conant, J. 1963. The education of American teachers. New York: McGraw-Hill.

Corbin, J. M., and A.L. Strauss 2008. Basics of qualitative research: Techniques and procedures for developing grounded theory. 3rd ed. Los Angeles, CA: Sage.

Culpan, I., N. Draper, and S. Stevens. 2011. Physical Education, Exercise Science and Pedagogy: Forging the Links. International Journal of Sport and Health Science 9: 54-63

Dyson, B. 2002. The implementation of cooperative learning in an elementary physical education program. Journal of Teaching in Physical Education 22, no. 1: 6985. 
Dyson, B. 2001. Cooperative learning in an elementary physical education program. Journal of Teaching in Physical Education 20, no. 3: 264-281.

Dyson, B., and A. Casey. 2012. Cooperative Learning in Physical Education: A research-based approach. London: Routledge.

Dyson, B. P., N.R. Linehan, and P.A. Hastie. 2010. The ecology of cooperative learning in elementary physical education classes. Journal of Teaching in Physical Education 29 no. 2: 113-30.

Green, K. 2005. Examinations: a 'new orthodoxy' in physical education. In Physical education: essential issues, ed. K. Green and K. Hardman, 143-160. London, Sage.

Green, K. 2001. Examinations in physical education: a sociological perspective on a 'new orthodoxy', British Journal of Sociology of Education, 22 no. 1: 51-73.

Hendry, G.D. 1996. Constructivism and Educational Practice. Australian Journal of Education, 40 no. 1: 19-45.

Henry, F. 1964. Physical education - An academic discipline. Journal of Health, Physical Education and Recreation 35: 32-33.

Hoffman, S. 1987. Dreaming the impossible dream: The decline and fall of physical education. In Trends toward the future in physical education, ed. J. Massengale 121-135. Champaign, IL: Human Kinetics.

Kirk, D. 1998. Educational Reform, Physical Culture and the Crisis of Legitimation in Physical Education. Discourse: Studies in the Cultural Politics of Education, 19 no. 1: 101-112.

Kirk, D. 2010. Physical education futures. Milton Park, Abingdon, Oxon: Routledge.

Lee, C., T. O’Donovan, E. Choi, and D. Kirk. 2012. The Knowledge Base for Physical Education Teacher Education (PETE): A Comparative Study of University Programmes in England and Korea. International Convention on Science, Education \& Medicine in Sport Scottish Exhibition \& Conference Centre, Glasgow, UK 19-24 July 2012

Locke, L. 1992. Changing secondary school physical education. Quest 44 no. 3: 361372.

Macdonald, D., and R. Brooker 1999. Assessment issues in a performance-based subject : A case study of physical education. In Learners, Learning and Assessment. ed. P. Murphy. 171-190. London: Sage.

MacPhail, A. 2004. The social construction of Higher Grade Physical Education: the impact of teacher curriculum decision-making, Sport, Education and Society, 9 no. 1: 53-73. 
MacPhail, A. 2007. Teachers' views on the construction, management and delivery of an externally prescribed physical education curriculum: Higher Grade Physical Education. Physical Education and Sport Pedagogy, 12 no. 1: 43-60

Penney, D., and J. Evans 2013. Who is physical education for? In debates in physical education. ed. S. Capel and M. Whitehead, 157-170. London: Routledge.

Penney, D., A. Jones, P. Newhouse, and A. Cambell. 2012. Developing a digital assessment in senior secondary physical education. Physical Education and Sport Pedagogy, 17 no. 4: 383-410.

Reid, A. 1996a. The concept of physical education in current curriculum and assessment policy in Scotland. European Physical Education Review, 2: 7-18.

Reid, A. 1996b. Knowledge, practice and theory in physical education. European Physical Education Review, 2: 94-104.

Rimmer, V. 2013. What is success in physical education and how can this be best be achieved? In debates in physical education. ed S. Capel and M. Whitehead, 89106. London: Routledge.

Rose, D. A. 1986. Is there a discipline of physical education? Quest, 30: 1-21.

Sallis, J.F., T.L. McKenzie, M.W. Beets, A. Beighle, H. Erwin, and L. Lee. 2012. Physical Education's Role in Public Health: Steps Forward and Backward Over 20 Years and HOPE for the Future. Research Quarterly for Exercise and Sport. 83 no. 2: 125-135.

Shulman, L. 1987. Knowledge and teaching: Foundations of the new reform. Harvard Educational Review, 57 no. 1: 1-22.

Siedentop, D. 2002. Content knowledge for physical education. Journal of Teaching in Physical Education 21, no. 4: 368-377.

Sloan, K. 2008 The expanding educational services sector: neoliberalism and the corporatization of curriculum at the local level in the US. Journal of Curriculum Studies, 40 no. 5: 555-578.

Thorburn, M. 2007. Achieving conceptual and curriculum coherence in high-stakes school examinations in Physical Education. Physical Education and Sport Pedagogy. 12 no. 2: 163-184.

Thorburn, M. 2004. Providing 'opportunity for all' through Higher Still: a continuing challenge for physical education in Scotland, Scottish Educational Review, 24: 66-78.

Thorburn, M., N. Carse, M. Jess, and M. Atencio. 2011. Translating change into improved practice: Analysis of teachers' attempts to generate a new emerging pedagogy in Scotland. European Physical Education Review, 17 no. 3: 313324. 
Thorburn, M., and D. Collins. 2003. Integrated curriculum models and their effects on teachers' pedagogy practices. European Physical Education Review, 9 no. 2: 185-209.

Tinning, R. 2002. Engaging Siedentopian Perspectives on Content Knowledge for Physical Education. Journal of Teaching in Physical Education, 21: 378-391

Tinning, R. 2009. Who pushed humpty dumpty? Dilemmas in physical education circa 2007. In Historic Traditions and Future Directions of Research on Teaching and Teacher Education in Physical Education. ed. L.D. Housner, M.W. Metzler, P.G. Schempp, and T.J. Templin, 149-154. Morgantown, MV: Fitness Information Technology.

Velija, P. \& Kumar, G. 2009. GCSE physical education and the embodiment of gender. Sport, Education and Society. 14 (4): 383-399.

Vickers, J. (1987). The role of subject matter in the preparation of teachers in physical education. Quest, 39, 179-184. 


\begin{tabular}{|c|c|c|c|c|}
\hline Qualification & $\begin{array}{l}\text { Unit } \\
\text { (Assessment method) }\end{array}$ & Examination & $\begin{array}{l}\text { Sections } \\
\text { (20\% of total mark) }\end{array}$ & Components \\
\hline $\begin{array}{l}\text { Advanced } \\
\text { Subsidiary }\end{array}$ & $\begin{array}{l}\text { An Introduction to } \\
\text { Physical Education } \\
\text { (Externally Set and } \\
\text { Assessed Examination) }\end{array}$ & \multirow{3}{*}{$\begin{array}{l}\text { - } 60 \% \text { of the } \\
\text { Total Mark } \\
\text { Two Hour Written } \\
\text { Paper } \\
\text { sections with one } \\
\text { question in each } \\
\text { section } \\
\text { Candidates must } \\
\text { answer all parts of } \\
\text { the question in each } \\
\text { of the sections A, B } \\
\text { and C to } \\
\text { Demonstrate } \\
\text { knowledge-analysis } \\
\text { and Evaluation }\end{array}$} & $\begin{array}{l}\text { Anatomy and } \\
\text { Physiology (Section } \\
\text { A) }\end{array}$ & $\begin{array}{l}\text { The Skeletal and } \\
\text { Muscular Systems }\end{array}$ \\
\hline \multirow[t]{2}{*}{ Advanced } & \multirow[t]{2}{*}{$\begin{array}{l}\text { Acquiring, Developing } \\
\text { and Evaluating Practical } \\
\text { Skills in Physical } \\
\text { Education } \\
\text { (Externally Set, Internally } \\
\text { Assessed and Externally } \\
\text { Moderated) }\end{array}$} & & $\begin{array}{l}\text { Acquiring } \\
\text { Movement Skills } \\
\text { (Section B) }\end{array}$ & $\begin{array}{l}\text { Motion and } \\
\text { Movement }\end{array}$ \\
\hline & & & $\begin{array}{l}\text { Socio-Cultural } \\
\text { Studies relating to } \\
\text { participation in } \\
\text { Physical Activity } \\
\text { (Section C) }\end{array}$ & $\begin{array}{l}\text { The cardiovascular } \\
\text { and Respiratory } \\
\text { Systems in relation } \\
\text { to the performance } \\
\text { of physical activity }\end{array}$ \\
\hline
\end{tabular}

3 Table 1: Course Overview (Summarised from OCR Specification for Advanced and Advanced Subsidiary Physical Education) 
${ }^{\text {i }}$ Advanced Subsidiary Level (AS Level) is the first part of the current A Level qualification students take at the end of their schooling in the UK

ii the Office for Standards in Education (Ofsted) is the official body for inspecting schools in the UK.

iii The General Certificate of Secondary Education is the qualification taken at the end of compulsory education at the age of 16

iv The Business and Technology Education Council courses can be taken as well as, or in place of, GCSEs and A levels. They were designed to be a work related qualification designed around employers' needs, but which also allow for progression to university. Students engage in more practical, real-world learning alongside key theoretical background knowledge. 